\title{
BMJ Open Revisit the correlates of infant mortality in Bangladesh: findings from two nationwide cross-sectional studies
}

\author{
Md Mahabubur Rahman, ${ }^{1}$ Tasnim Ara (ib , ${ }^{1}$ Sultan Mahmud (D) , ${ }^{1}$ Nandeeta Samad ${ }^{2}$
}

To cite: Rahman MM, Ara T, Mahmud S, et al. Revisit the correlates of infant mortality in Bangladesh: findings from two nationwide crosssectional studies. BMJ Open 2021;11:e045506. doi:10.1136/ bmjopen-2020-045506

- Prepublication history for this paper is available online. To view these files, please visit the journal online (http://dx.doi org/10.1136/bmjopen-2020045506).

Received 02 October 2020 Accepted 31 July 2021

Check for updates

(C) Author(s) (or their employer(s)) 2021. Re-use permitted under CC BY-NC. No commercial re-use. See rights and permissions. Published by BMJ.

${ }^{1}$ Institute of Statistical Research and Training, University of Dhaka, Dhaka, Bangladesh ${ }^{2}$ Department of Public Health, North South University, Dhaka, Bangladesh

Correspondence to Tasnim Ara; tara@isrt.ac.bd

\section{ABSTRACT}

Objective The main objective of this study is to investigate how the direction and strength of the association between infant mortality and its predictors are changing over time in Bangladesh using a nationally representative sample for the period 2011-2014.

Design, setting and participants Data from two repeatedly cross-sectional Bangladesh Demographic and Health Surveys (BDHSs) for the years 2011 and 2014 were used. A total of 7664 (with 312 infant death) and 7048 (with 264 infant death) complete cases, respectively, from BDHS 2011 and 2014 datasets were included in the study. Methods Cox's proportional hazard model with robust standard error (SE) that adjusts for the complex survey design characteristics was implemented to assess how the risk factors associated with infant mortality change their paths. Results Results reflected that administrative division remained as a potential risk factor of infant death for both periods. Household's socioeconomic status, father's employment status, age difference between parents turned out to be potential risk factors in 2014, though they did not show any significant association with infant death in the year 2011. In contrast to 2011, mothers' individuallevel characteristics such as age at childbirth, education, media exposure, employment status did not remain as significant risk factors for infant death in 2014. Younger fathers increased the burden of death among infants of adolescent mothers. At higher order births, the burden of infant death significantly shifted from rural to urban areas. From the year 2011 to 2014 , urban areas achieved socioeconomic equity in infant survival, while the extent of inequity was increased in rural areas.

Conclusion Community-based programmes should be designed for urban mothers who are expecting higher order births. To eradicate the socioeconomic inequity in infant survival, the government should design strong and sustainable maternal and child healthcare facilities, especially for rural areas.

\section{INTRODUCTION}

Infant mortality is defined as the death of children who die before the age of one and is considered one of the most important elements of population change. ${ }^{1}$ Infant mortality also can be a demonstrator for narrating the overall social and socioeconomic well-being ${ }^{2}$ of a country, as well as the progress of child health. ${ }^{3}$ The global infant

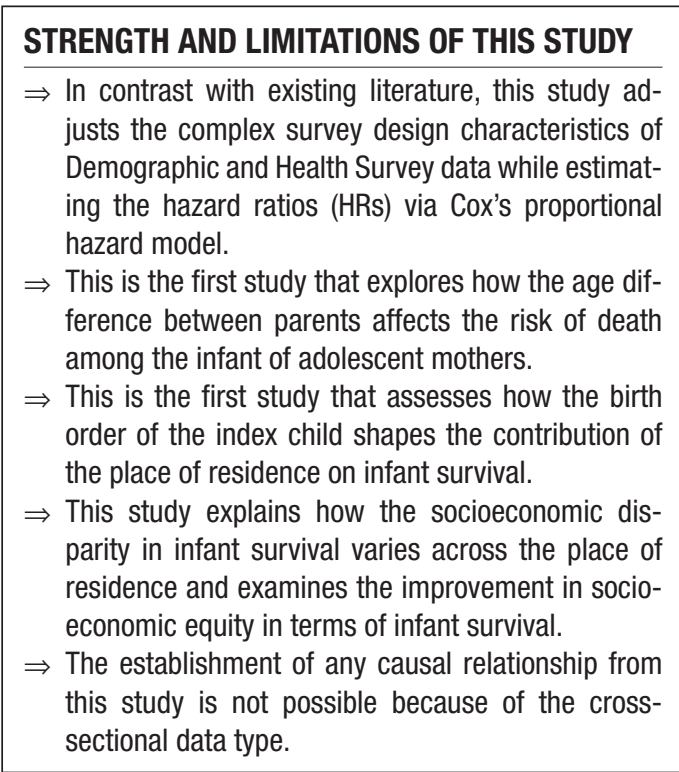

mortality rate was 32.5 per 1000 live births in 2015. The annual infant mortality rate was reduced by $21.3 \%$ between 2000 and 2015. ${ }^{4}$ Over the last few decades, Bangladesh experienced an immense reduction in child mortality. ${ }^{5}$ However, the decrease in infant mortality ( 87 per 1000 live births in 1990 to 38 per 1000 live births in 2014) is slower than in under-five children (133 per 1000 live births in 1990 to 46 per 1000 live births in 2014) over the last 21 years. ${ }^{6}$ More importantly, neonatal mortality rate also has declined over time (52 per 1000 live births in 1990 to 28 per 1000 live births in 2014) which has a significant role in infant death. ${ }^{6}$ For achieving Sustainable Development Goals (SDGs), it is crucial to reduce infant mortality to at least as low as 5 per 1000 live births (defined as a threshold by the Rural Electrification Board ${ }^{6}$ ).

Infant mortality has a significant association with socioeconomic and demographic factors in developing countries. ${ }^{7}$ In Bangladesh, as in many low-income and middleincome countries, child survival and health have made some progress in the current 
era. ${ }^{8-10}$ Furthermore, there are several responsible factors still influencing infant mortality in Bangladesh to keep it high. Socioeconomic inequality is such a leading factor of mortality in infants. ${ }^{11}$ Multiple births, access to pure drinking water, and receiving prenatal care also have a substantial influence on infant mortality. ${ }^{10}$ Some other set of factors such as mother's age at childbirth, parity and breastfeeding status also have significant effects on infant mortality. ${ }^{12}$ Those factors also have been found as significant determinants of high infant mortality in different countries. For instance, limited access to pure drinking water, sanitation, gender, and social discrimination are the most important factors for high infant mortality in Pakistan. ${ }^{13}$ The sociodemographic, sanitation and maternal variables also have been found as significant determinants of high infant and child mortality in Zimbabwe. ${ }^{14}$ In rural regions of India, social class, mother's education and women's empowerment have been identified as significant factors for infant survival. ${ }^{15}$ Besides, a similar set of determinants of infant mortality has been found from several studies in Kenya, ${ }^{16} \mathrm{Nepal},{ }^{17}$ as well as in Turkey. ${ }^{18}$

As an important marker of public health, infant mortality reveals the weakness of the health system of Bangladesh. Nevertheless, the research on this health issue is inadequate in Bangladesh to identify the potential determinants or factors for this extremely high infant mortality. Very few studies have been done regarding this issue that adopts the time-to-event data modelling. To the best of our knowledge, none of these studies had adjusted the complex survey design characteristics (weighting, stratification and clustering) that were needed to reduce the bias while estimating the hazard of infant deaths from time-to-event-data. These studies showed the association of infant survival with a limited number of risk factors. Along with maternal age, paternal age might be a key instrument for child survival. ${ }^{19}$ The risk of infant death among adolescent mothers might get severe if the father of the infant is also young. As this proposition is still not established, it is essential to explore the impact of 'age difference between parents' on infant survival. It is widely recognised that irrespective of the place of residence, the risk of death is higher among the children of first birth order. ${ }^{20}$ In rural areas, mothers give birth to their first child earlier than the mothers from urban areas..$^{20}$ Thus, at higher birth orders, mothers from urban areas get comparatively older than the mothers from rural areas. Hence for higher birth orders, in comparison to the infants of rural areas, a lower likelihood of survival might be observed among infants of urban areas. Nevertheless, to the best of our knowledge, no studies have inspected how parity modifies the association between place of residence and infant mortality. In Bangladesh, healthcare facilities are inequitably distributed in favour of urban areas, ${ }^{21} 22$ which gives the urban poor community somewhat easier access to healthcare facilities. Therefore, it might be seen that compared with the urban areas, the intensity of socioeconomic disparity in infant survival is much higher in rural areas. However, there is still a research gap to answer the following questions: 'How the socioeconomic disparity in infant survival varies across the place of residence? Is there any indication of socioeconomic equity in infant survival?'. In these circumstances, to design effective policy intervention programmes to reduce infant mortality at a faster pace, it is essential to know how the risk factors of infant mortality are changing their paths over time. Therefore, to ensure sustainable improvement in infant survival, this study aims to fill all the mentioned existing research gaps by revisiting the correlates of infant deaths using the appropriate statistical model.

\section{MATERIALS AND METHODS \\ Data}

This study is based on the most recent nationally representative Bangladesh Demographic and Health Surveys (BDHSs): 2011 and 2014..$^{20}$ These repeatedly crosssectional surveys were designed to collect detailed information on a wide range of indicators including maternal and child health. These surveys were conducted in collaboration with the National Institute of Population Research and Training, ICF International, USA, and Mitra \& Associates. In BDHSs, a two-stage stratified sampling was used, where at the first stage, 600 enumeration areas (EAs) were selected with probability proportional to size within two main sampling strata- urban and rural areas. At the second stage, a systematic sample of 30 households (on average) was selected per EA.

\section{Outcome measures}

In this study, we included children born within the preceding 5 years from the survey years. Among these children, who died before reaching their first birthday were treated as events. Children who died at or after their first birthday and who were alive at the time of the interview (reached at least their first birthday or did not reach their first birthday) were considered as censored cases during the analysis. In DHS data, the B5 and B6 variables, respectively, indicate survival status and the age at death for the dead children. To calculate the failure time, we converted the unit of the $\mathrm{B} 6$ variable in days. To calculate the survival time (in days) for the alive children, we subtracted the date of birth (B3 in DHS) from the date of the interview (V008 in DHS) and multiplied the result by $365 / 12$. Survival time for the children who survived at least their first birthday (might be dead or alive at the time of interview) was replaced with 365 , as the children who died before reaching their first birthday were considered as failure cases.

\section{Covariates from the BDHS data}

To address the mentioned research gaps, the choice of predictor variables of infant death was made based on the existing literatures from Bangladesh, ${ }^{11}{ }^{12} 24-28$ Pakistan, ${ }^{13}$ India ${ }^{15}$ and Nepal. ${ }^{17}$ The independent variables were mainly 
divided into four broad categories such as demographic, household, parental and child-related factors.

\section{Demographic factors}

Bangladesh is classified into different geographical boundaries, where administrative division is the highest level and BDHS data are representative at the division level. Each division is divided into zilas, and each zila into upazilas. Upazilas were then divided into wards or union parishads (UPs). These wards and UPs within an upazila formed rural and urban area, respectively. These divisions allow the country as a whole to be separated into rural and urban areas. Demographic covariates of this study were categorised in the following way: Administrative divisions: Dhaka, Chittagong, Barisal, Khulna, Rajshahi, Rangpur, Sylhet; Residence: Rural, Urban; and Religion: Muslims, Others.

\section{Household-related factors}

The wealth quintiles (WQs) is a composite measure of household assets which was constructed through principal components analysis. Household-related factors were categorised as follows: Wealth index: Poor (1-40th percentile of WQs), Middle (41-60th percentile of WQs), Rich (above 60th percentile of WQs); Source of drinking water: Unsafe (dug well/unprotected well/surface water/ unprotected spring/river/dam/lake/ponds/stream/ canal/irrigation channel/tanker truck/cart with small tank), Safe (piped water/piped into dwelling/piped to yard or plot/public tap/standpipe/tube well water/ tube well or borehole/protected well/protected spring/ rainwater/rainwater); Family size: Small (the number of family members other than living children is less or equal to the number of living children), Large (otherwise).

\section{Parental factors}

We did not have data on mother's knowledge about maternal and child healthcare, but maternal education and media exposure can serve as a reasonable proxy of it. Parental factors were categorised as follows: Mother's education: No education (no formal education), Primary (1-5 years of formal schooling), Secondary (6-10 years of formal schooling), Higher (above secondary); Mother's media exposure: Yes (mother was either watching TV or listening radio or reading newspaper at least once a week), No (otherwise); Mother's employment status: Unemployed, Employed; Mother's age at birth of the index child: <18/18-22/23-27/28-32/33+; Father's employment status: Unemployed, Employed; Age difference between parents: $0-5 / 6+$.

\section{Child factors}

Sex of the index child: Female, Male; Birth order of the index child: $1 / 2 / 3+$.

\section{Statistical analysis}

All the statistical analysis was carried out over 7664 (with 312 infant death) and 7048 (with 264 infant death) complete cases respectively from BDHS 2011 and 2014 datasets. Bivariate analysis based on the Kaplan-Meier logrank test ${ }^{29}{ }^{30}$ was performed to explore the distribution of infant mortality among different groups of predictors. After adjusting for the complex survey design characteristics of DHS data, a Cox's proportional hazard (PH) model with robust standard error (SE) was fitted to assess the association between infant mortality and its predictors. Cox' PH model was used in the analysis, as the primary estimate of interest was the hazard ratios (HRs) instead of a relative risk from the Poisson model. However, similar to a study on infant mortality from Ghana, ${ }^{31}$ a sensitivity analysis was performed to assess whether the results obtained were robust to the model specification. By setting the survival time as exposure, a modified Poisson with robust SE that adjusts for complex survey design characteristics of DHS was implemented as a sensitivity analysis.

All statistical analyses were performed using Stata V.14 (Stata SE V.14, Stata Corp, College Station, Texas, USA).

\section{Patient and public involvement}

No patients were involved during the development of the research questions, outcome measurement and study design. Results of this research could not be disseminated to the study participants.

\section{RESULTS}

Results on the prevalence of infant mortality between surveys Table 1 presents the prevalence of infant mortality by some sociodemographic characteristics of the infants and their parents for the years 2011 and 2014. The result of the present study found that the prevalence of infant mortality remained considerably high in the Sylhet division for both periods. No significant disparity in infant survival was observed between rural and urban areas. The prevalence of infant mortality was significantly associated with the household's socioeconomic status. It was observed that the prevalence of infant mortality from poor households was consistently higher than the wealthier households. Prevalence of infant death did not vary much by family size. The prevalence of infant mortality decreased by better education and media exposure of mothers, whereas maternal employment status negatively contributed to infant survival. Among mothers aged less than 27 years, the rate of infant death was decreased by the mother's age, whereas an opposite direction of association was observed when the mother's age exceeded 27 years. Father's employment status and the age difference between parents were found to be significantly associated with infant death for the year 2014. The sex of children was significantly associated with infant death for the year 2011, whereas in 2014 no such association was observed. The prevalence of infant death was substantially higher at first birth order for both periods.

\section{Results on the role of parental age and birth order on infant} death

Figure 1 displays that around $40 \%$ of mothers gave their first birth before 18 years of age, which could be 
Table 1 Descriptive statistics: Results from Kaplan-Meier log-rank test

\begin{tabular}{|c|c|c|c|c|c|c|c|}
\hline \multirow[b]{2}{*}{ Factors } & & \multicolumn{3}{|c|}{ BDHS 2011} & \multicolumn{3}{|c|}{ BDHS 2014} \\
\hline & & $\mathbf{N}$ & $\begin{array}{l}\% \text { of infant } \\
\text { death }\end{array}$ & $\begin{array}{l}\chi^{2} \text { value } \\
\text { ( } p \text {-value) }\end{array}$ & $\mathbf{N}$ & $\begin{array}{l}\% \text { of infant } \\
\text { death }\end{array}$ & $\begin{array}{l}\chi^{2} \text { value } \\
\text { (p-value) }\end{array}$ \\
\hline \multicolumn{2}{|l|}{ Total } & 7664 & 4.07 & - & 7048 & 3.74 & - \\
\hline \multicolumn{8}{|l|}{ Demographic factors } \\
\hline \multirow[t]{7}{*}{ Administrative division } & Dhaka & 1280 & 3.98 & \multirow[t]{7}{*}{$12.14(0.059)$} & 1229 & 2.85 & \multirow[t]{7}{*}{$12.91(0.045)$} \\
\hline & Chittagong & 1500 & 3.20 & & 1346 & 3.49 & \\
\hline & Barisal & 835 & 4.19 & & 811 & 2.71 & \\
\hline & Khulna & 842 & 3.33 & & 762 & 4.33 & \\
\hline & Rajshahi & 935 & 4.39 & & 839 & 3.81 & \\
\hline & Rangpur & 1006 & 3.78 & & 862 & 3.83 & \\
\hline & Sylhet & 1266 & 5.61 & & 1199 & 5.17 & \\
\hline \multirow[t]{2}{*}{ Place of residence } & Rural & 5316 & 4.03 & \multirow[t]{2}{*}{$0.10(0.751)$} & 4811 & 3.87 & \multirow[t]{2}{*}{$0.64(0.426)$} \\
\hline & Urban & 2348 & 4.17 & & 2237 & 3.49 & \\
\hline \multirow[t]{2}{*}{ Religion } & Muslim & 6894 & 4.02 & \multirow[t]{2}{*}{$0.47(0.492)$} & 6466 & 3.77 & \multirow[t]{2}{*}{$0.20(0.657)$} \\
\hline & Others & 770 & 4.55 & & 582 & 3.44 & \\
\hline \multicolumn{8}{|l|}{ Household-related factors } \\
\hline \multirow[t]{3}{*}{ Wealth index } & Poor & 3266 & 4.72 & \multirow[t]{3}{*}{$6.73(0.035)$} & 2921 & 4.66 & \multirow[t]{3}{*}{$12.10(0.002)$} \\
\hline & Middle & 1428 & 3.99 & & 1335 & 3.45 & \\
\hline & Rich & 2970 & 3.40 & & 2792 & 2.94 & \\
\hline \multirow[t]{2}{*}{ Source of drinking water } & Unsafe & 147 & 4.08 & \multirow[t]{2}{*}{$0.00(0.999)$} & 175 & 4.57 & \multirow[t]{2}{*}{$0.30(0.585)$} \\
\hline & Safe & 7517 & 4.07 & & 6873 & 3.72 & \\
\hline \multirow[t]{2}{*}{ Family size } & Small & 129 & 5.43 & \multirow[t]{2}{*}{$0.56(0.455)$} & 115 & 3.48 & $0.02(0.883)$ \\
\hline & Large & 7535 & 4.05 & & 6933 & 3.75 & \\
\hline Parental factors & & & & & & & \\
\hline Mother's education & No education & 1565 & 5.50 & $16.68(0.001)$ & 1142 & 4.55 & $10.07(0.018)$ \\
\hline & Primary & 2370 & 4.43 & & 1991 & 4.17 & \\
\hline & Secondary & 3154 & 3.42 & & 3214 & 3.61 & \\
\hline & Higher & 575 & 2.26 & & 701 & 1.85 & \\
\hline Mother's media exposure & No & 2869 & 4.43 & $1.45(0.229)$ & 2816 & 4.33 & $4.55(0.033)$ \\
\hline & Yes & 4795 & 3.86 & & 4232 & 3.36 & \\
\hline Mother's employment & Unemployed & 6905 & 3.87 & $7.10(0.008)$ & 5245 & 3.58 & $1.35(0.246)$ \\
\hline status & Employed & 759 & 5.93 & & 1803 & 4.22 & \\
\hline Mother's age at birth of & $<18$ & 1159 & 4.92 & $15.39(0.004)$ & 1106 & 4.70 & $9.19(0.057)$ \\
\hline index child (in years) & $18-22$ & 2807 & 4.74 & & 2487 & 3.90 & \\
\hline & $23-27$ & 1993 & 2.66 & & 1901 & 2.74 & \\
\hline & 28-32 & 1100 & 4.00 & & 1035 & 3.77 & \\
\hline & $33+$ & 605 & 4.13 & & 519 & 4.62 & \\
\hline Father's employment & Unemployed & 105 & 1.90 & $1.28(0.257)$ & 41 & 14.63 & $14.43(0.001)$ \\
\hline status & Employed & 7559 & 4.10 & & 7007 & 3.68 & \\
\hline Age difference between & $0-5$ & 2083 & 3.98 & $0.05(0.820)$ & 2108 & 5.12 & $16.10(0.001)$ \\
\hline parents & $6+$ & 5581 & 4.10 & & 4940 & 3.16 & \\
\hline Child factors & & & & & & & \\
\hline Sex of index child & Female & 3722 & 3.47 & $6.94(0.009)$ & 3415 & 3.54 & $0.80(0.37)$ \\
\hline & Male & 3942 & 4.64 & & 3633 & 3.94 & \\
\hline
\end{tabular}


Table 1 Continued

\begin{tabular}{|c|c|c|c|c|c|c|c|}
\hline \multirow[b]{2}{*}{ Factors } & & \multicolumn{3}{|c|}{ BDHS 2011} & \multicolumn{3}{|c|}{ BDHS 2014} \\
\hline & & $\mathbf{N}$ & $\begin{array}{l}\% \text { of infant } \\
\text { death }\end{array}$ & $\begin{array}{l}\chi^{2} \text { value } \\
\text { (p-value) }\end{array}$ & $\mathbf{N}$ & $\begin{array}{l}\% \text { of infant } \\
\text { death }\end{array}$ & $\begin{array}{l}\chi^{2} \text { value } \\
\text { (p-value) }\end{array}$ \\
\hline \multirow{2}{*}{ Birth order of index child } & 2 & 2239 & 3.53 & \multirow{2}{*}{$2.59(0.274)$} & 2142 & 3.03 & \multirow{2}{*}{$4.98(0.083)$} \\
\hline & $3+$ & 2905 & 4.17 & & 2308 & 3.81 & \\
\hline
\end{tabular}

BDHS, Bangladesh Demographic and Health Survey; N, Number of infants in the analytical sample.

a possible reason behind observing the highest rate of infant mortality at first birth (table 1 ). The lowest rate of infant death was observed at second birth order (table 1), where only around $6 \%$ of mothers were younger than 18 years and more than $80 \%$ of mothers were between 18 and 27 years old (figure 1). In the year 2014, among mothers aged less than 18 years, the percentage of infant death was 4.7 (table 1 ). Figure 2 reveals that, among them, who had at most 5 years of age difference with their husbands experienced a considerably higher prevalence of infant mortality than those who had more than 5 years of age difference with their husbands (prevalence $7.6 \%$ vs $3.9 \%)$. These findings indicate that younger fathers worsen the burden of death among the infant of adolescent mothers.

\section{Results on the correlates of infant mortality in 2011 and 2014}

Table 2 reveals the potential risk factors associated with infant mortality in Bangladesh for the years 2011 and 2014. Cox's PH model with robust SE that adjusts for the complex survey design characteristics was fitted to assess how the direction and magnitude of the association between infant mortality and its predictors were changing over time. Crude HRs along with the p-values were estimated for all the considered factors for both periods. Significant factors were retained in the multivariable models to estimate the adjusted HRs. A similar fashion of results were also observed when a sensitivity analysis was performed by estimating the adjusted relative risk from the modified Poisson regression model with robust SE that adjusts for the complex survey design characteristics.

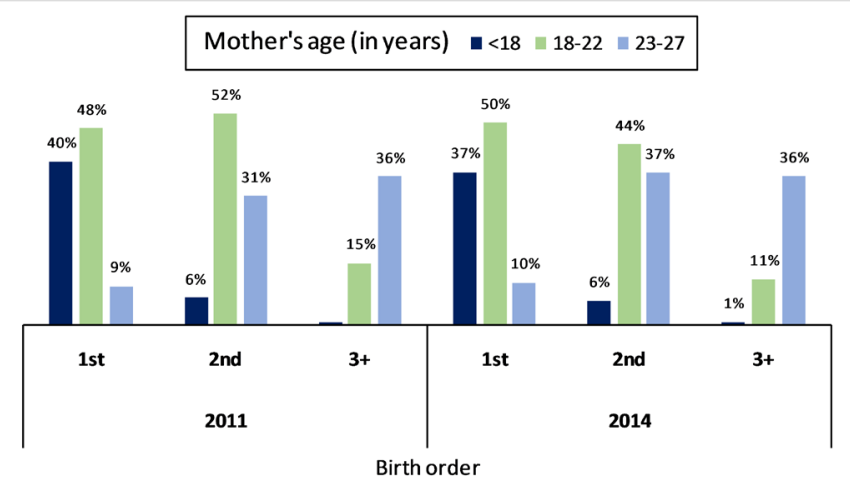

Figure 1 Distribution of mother's age by birth order.
Significant regional heterogeneity was observed for both periods. The findings of this study revealed that in the year 2011, the likelihood of infant mortality was $44 \%$ (adjusted HR (aHR) $=1.44,95 \%$ CI 0.99 to 2.08) higher among children from the Sylhet division when compared with the Dhaka division. The risk of infant deaths even increased in 2014 for the Sylhet division ( $\mathrm{aHR}=1.69,95 \%$ CI 1.04 to 2.75). In 2011, compared with the Dhaka division, the hazard rate of infant death was not significantly higher in Khulna. However, in 2014, it was found that the hazard rate in Khulna ( $\mathrm{aHR}=1.60,95 \%$ CI 0.95 to 2.69) turned out to be significantly higher than Dhaka. In 2011, household's socioeconomic status was not significantly associated with infant death. However, in 2014, infant survival significantly varied by the household's socioeconomic status. For example, the risk of death was about $35 \%$ lower among children of rich households compared with poor households.

Expectedly, maternal education plays a fundamental role in infant mortality. From the results, it was observed that in 2011, the hazard rate of infant mortality significantly declined by the better educational involvement of mothers. Importantly, in 2014, no significant heterogeneity in infant survival was noticed by maternal education. Though the crude effect of mother's media exposure was significant only in the year 2014, it did not remain as a significant risk factor in the adjusted model. The results indicated that in 2011, mother's employment had a negative impact on infant survival. The infants of working

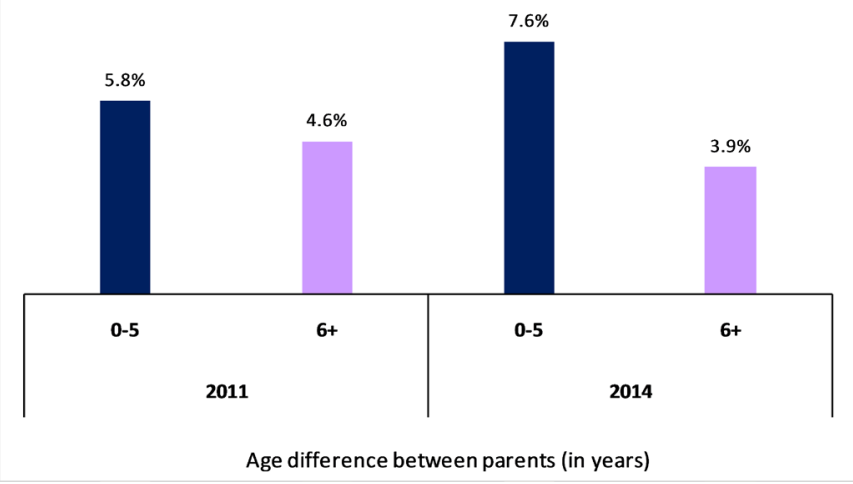

Figure 2 Prevalence of infant mortality among mothers of age less than 18 years by the age difference between parents. 


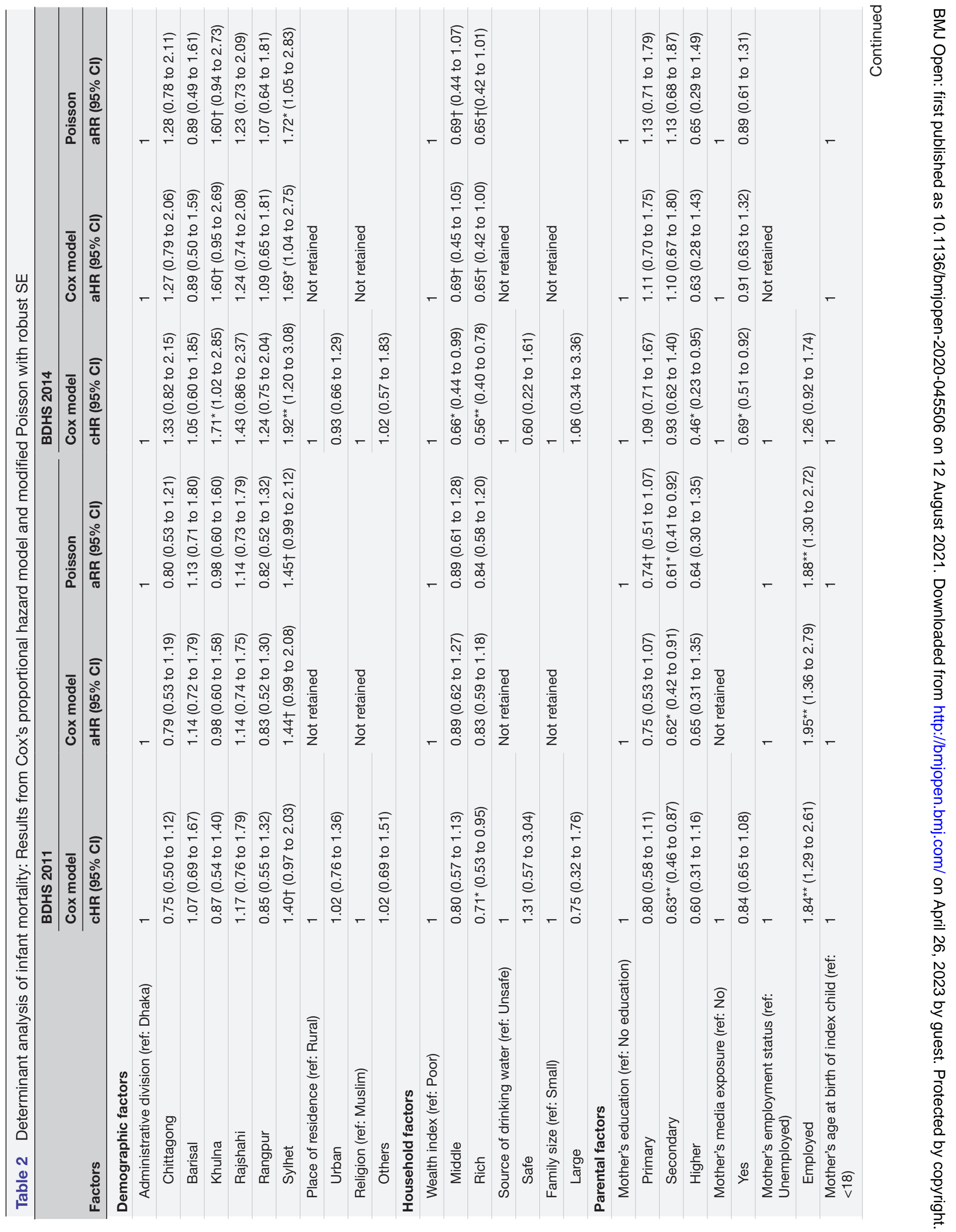




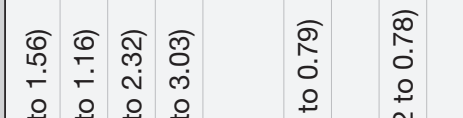

담

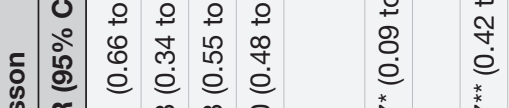

둥

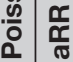

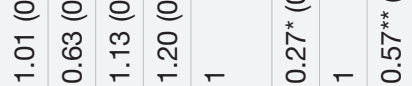

ช

咅

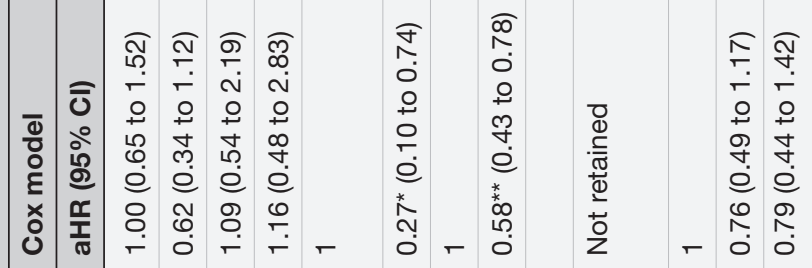

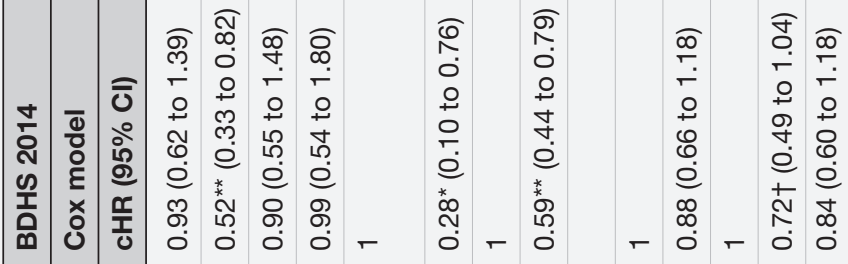

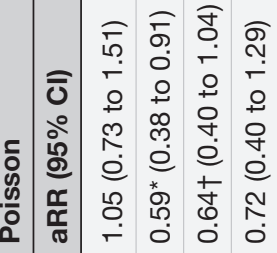

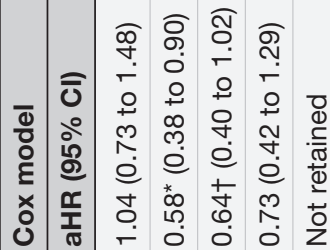

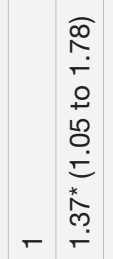

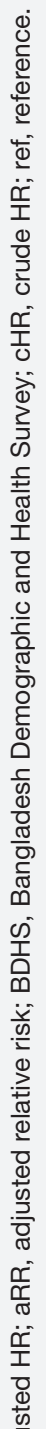

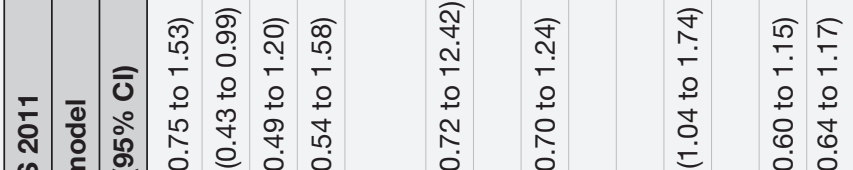

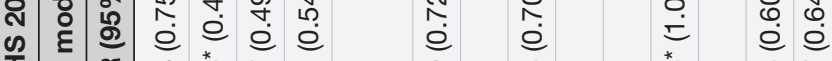

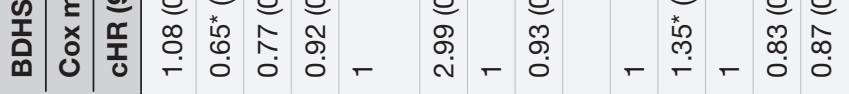

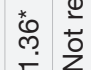

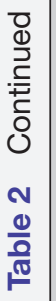
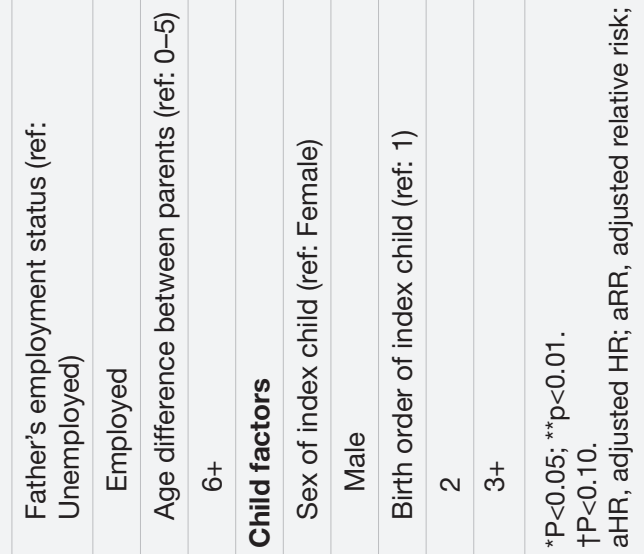


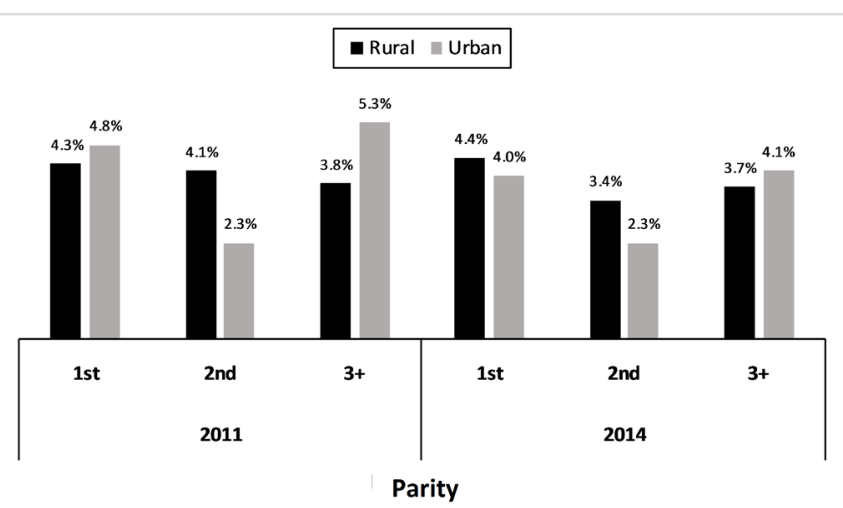

Figure 3 Prevalence by place of residence and parity.

mothers were almost two times more likely to die before their first birthday than those from unemployed mothers. However, in 2014, mother's employment status did not remain a significant risk factor of infant death.

Results reflected that in 2011, maternal age at birth of the index child was one of the key determinants of infant death. The findings revealed a higher risk of death among the infant of adolescent mothers. Infants from mothers aged 18 years or above had a considerably lower risk of dying compared with those born to mothers aged less than 18 years. The lowest hazard rate of infant death was observed among mothers aged between 23 and 27 years, whereas the risk of infant death slightly increased among mothers older than 27 years. Although it never exceeded the hazard experienced by adolescent mothers. However, in 2014, after adjusting the effect of other factors, no significant association was observed between mother's age at childbirth and infant death.

Results of 2014 revealed that paternal employment had a significant positive impact on infant survival. Compared with the infants of unemployed fathers, the hazard was $73 \%$ lower among infants of employed fathers $(\mathrm{aHR}=0.27$, $95 \%$ CI 0.10 to 0.74$)$. Importantly, it was found that in the year 2014, the age difference between parents was significantly associated with infant deaths. Parents whose age difference was more than 5 years were $42 \%$ less likely to experience an infant death, compared with the parents with at most 5 years of age gap $(\mathrm{aHR}=0.58,95 \%$ CI 0.43 to 0.78 ).

No gender effect was observed in 2014, though in 2011, a significant gender disparity in infant survival was observed in favour of the female child. Male children were more likely to die within the first year of life compared with female children (aHR=1.36, 95\% CI 1.05 to 1.76$)$. In 2014, after controlling the effect of other covariates, no significant difference in hazard rate was found by birth order, though a crude association was noticed previously.

\section{Does parity modify the association between place of residence and infant mortality?}

Figure 3 displays that in 2011, the prevalence of infant mortality did not vary much by the parity in rural areas, whereas urban areas showed some heterogeneity. At second and higher parity, there was a considerable difference in prevalence between rural and urban areas. In 2014, at any birth order, not much difference in infant mortality rates was noticed between urban and rural areas. Further, a stratum-specific analysis was conducted to examine the pattern of infant survival by the place of residence and parity. Table 3 demonstrates that, in 2011, no significant disparity in infant survival was found between rural and urban areas at first and second birth order. But, a significant disparity was observed for the following birth orders. Notably, for third and higher birth orders, the burden of infant deaths significantly shifted from rural to urban areas. However, in 2014, no such heterogeneity was observed between rural and urban areas, except for second birth order (crude HR=0.50, 95\% CI 0.26 to 0.96). Survey design adjusted modified Poisson with robust SE also yielded the same conclusion.

Is there any indication of socioeconomic equity in infant survival?

Figure 4 indicates that from the year 2011 to 2014, urban areas attained an improvement in socioeconomic equity

Table 3 Disparity by place of residence at different levels of parity: Results from Cox's proportional hazard model and modified Poisson with robust SE

\begin{tabular}{|c|c|c|c|c|c|}
\hline \multirow[b]{3}{*}{ Parity } & \multirow[b]{3}{*}{ Place of residence } & \multicolumn{2}{|l|}{ BDHS 2011} & \multicolumn{2}{|l|}{ BDHS 2014} \\
\hline & & Cox model & Poisson & Cox model & Poisson \\
\hline & & cHR (95\% CI) & cRR (95\% CI) & cHR (95\% Cl) & cRR (95\% CI) \\
\hline 1 & Urban & $0.98(0.62$ to 1.55$)$ & $0.98(0.61$ to 1.55$)$ & $1.16(0.71$ to 1.92$)$ & 1.18 (0.71 to 1.96$)$ \\
\hline 2 & Rural & 1 & 1 & 1 & 1 \\
\hline \multirow[t]{2}{*}{$3+$} & Rural & 1 & 1 & 1 & 1 \\
\hline & Urban & $1.46 \dagger(0.93$ to 2.35$)$ & $1.47 \dagger(0.92$ to 2.34$)$ & 0.98 (0.55 to 1.73$)$ & 1.00 (0.56 to 1.78$)$ \\
\hline
\end{tabular}




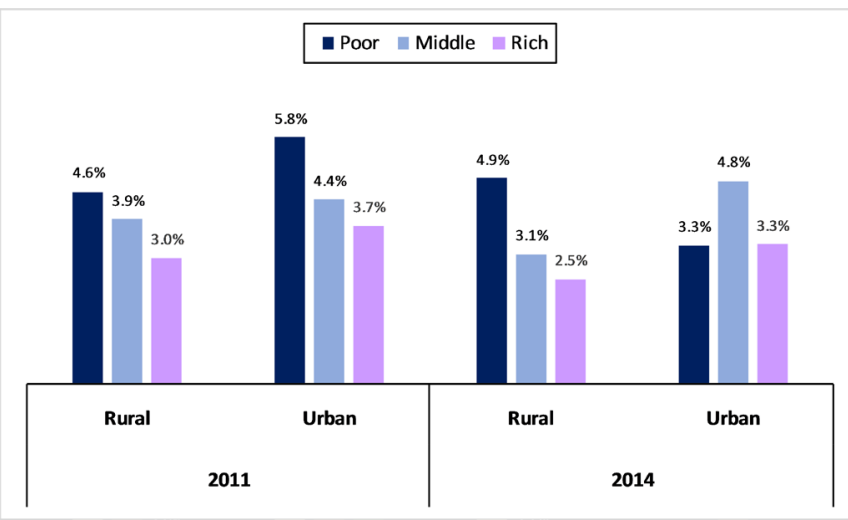

Figure 4 Prevalence by place of residence and household's socioeconomic status.

regarding infant survival, whereas an opposite scenario was noticed for rural areas. Table 4 provides insightful information regarding the existence and extent of socioeconomic heterogeneity in infant survival by the place of residence. Survey design adjusted Cox's PH model and Poisson regression, both of these statistical approaches yielded an indifferent conclusion. In 2011, the extent of association between socioeconomic status and infant mortality was quite similar in rural and urban areas. But, in 2014, significant socioeconomic heterogeneity in infant survival was found only in rural areas. It was observed that compared with the wealthier households, the likelihood of infant survival was significantly lower among the poor households of rural areas.

\section{DISCUSSION}

\section{Main findings}

As the rate of infant death in Bangladesh is still very high and it inhibits achieving SDGs, this study explores the paths of improving infant survival in the context of Bangladesh. Survey design adjusted Cox's PH model was employed to explore how the risk factors of infant death changed their paths from 2011 to 2014. From the year
2011 to 2014, socioeconomic disparity in infant survival was increased in rural areas, while a significant improvement in equity was noticed in urban areas. This is the first study that explores how the age difference between parents reduces the risk of infant death among adolescent mothers and reveals that the burden of infant death shifts from rural to urban areas, at third or higher birth order.

\section{Relationship between administrative divisions and infant mortality}

Our results confirm statistically significant regional heterogeneity in overall infant survival. Among the administrative divisions, Sylhet consistently showed lower infant survival than others, though a significant decline in infant mortality was observed over the years. High infant mortality in Sylhet division was observed due to many factors such as religious influence, superstitions, and lower awareness about infant and maternal healthcare. ${ }^{24}$ Moreover, this division was also lagged behind the other divisions regarding antenatal care, child delivery by skilled health professionals, and vaccination coverage among the children. ${ }^{24}$ In 2014, in addition to the Sylhet division, Khulna division also showed significantly higher infant mortality than others. Further study is suggested to identify the possible reasons for observing this higher rate of infant mortality in Khulna division.

\section{Relationship between parental age and infant mortality}

Maternal age at childbirth can influence infant survival through different perspectives. Infants of younger mothers face a higher risk of death because of their mother's immature reproductive systems and less stability to handle the complexities during childbirth. ${ }^{32}$ Above these, younger mothers are more likely to give birth to low-birth-weighted babies, ${ }^{33}$ which is considerably associated with a higher risk of infant death. ${ }^{34}$ Consistent with earlier studies, ${ }^{25}{ }^{35}$ our findings reveal that in the year 2011, there was a higher risk of infant death among younger mothers. However, in the year 2014, no such

Table 4 Socioeconomic disparity by place of residence: Results from Cox's proportional hazard model and modified Poisson with robust SE

\begin{tabular}{|c|c|c|c|c|c|}
\hline \multirow[b]{3}{*}{ Place of residence } & \multirow[b]{3}{*}{ Wealth index } & \multicolumn{2}{|l|}{ BDHS 2011} & \multicolumn{2}{|l|}{ BDHS 2014} \\
\hline & & Cox model & Poisson & Cox model & Poisson \\
\hline & & cHR $(95 \% \mathrm{Cl})$ & cRR $(95 \% \mathrm{Cl})$ & cHR (95\% CI) & cRR (95\% CI) \\
\hline \multirow{2}{*}{ Rural } & Middle & 0.84 (0.58 to 1.22$)$ & 0.84 (0.58 to 1.23$)$ & $0.63^{\star}(0.40$ to 0.99$)$ & $0.63^{\star}(0.39$ to 0.99$)$ \\
\hline & Rich & $0.65^{\star}(0.44$ to 0.97$)$ & $0.66^{*}(0.44$ to 0.98$)$ & $0.39^{\star *}(0.24$ to 0.63$)$ & $0.39^{\star *}(0.24$ to 0.63$)$ \\
\hline \multirow{2}{*}{ Urban } & Middle & $0.53(0.24$ to 1.18$)$ & 0.51 (0.23 to 1.16$)$ & 1.08 (0.39 to 2.93$)$ & 1.06 (0.38 to 2.93$)$ \\
\hline & Rich & $0.56 \dagger(0.31$ to 1.03$)$ & $0.55 \dagger(0.29$ to 1.02$)$ & $0.97(0.40$ to 2.36$)$ & 0.96 (0.39 to 2.37$)$ \\
\hline
\end{tabular}

${ }^{*} \mathrm{P}<0.0 ;{ }^{* *} \mathrm{p}<0.01$.

$+P<0.10$.

BDHS, Bangladesh Demographic and Health Survey; cHR, crude HR; cRR, crude relative risk. 
significant infant mortality differentials were observed by maternal age at childbirth. Importantly, our study results suggested that a substantial age gap between parents helped to improve infant survival, even when the mothers were adolescents. This finding could be explained by the fact that the younger fathers tend to be more likely to have financial constraints, compared with the older fathers, ${ }^{36}{ }^{37}$ which might result in inadequate healthcare facilities for mothers and newborns. Hence, to improve infant survival, extra attention should be given to adolescent mothers whose husbands are also younger.

\section{Relationship between maternal education and employment with infant mortality}

Mother's educational attainment is considered as one of the key indicators of infant survival. Educated mothers tend to have better socioeconomic status, good knowledge of childcare and more conscious about child illness and the effective use of modern healthcare services. ${ }^{15} 3839$ In addition, education helps to empower the mothers regarding maternal and child healthcare, which in turn plays a role in reducing child mortality. ${ }^{2640}$ Similar to other studies, ${ }^{927} 28$ a higher risk of infant death has been observed among illiterate mothers compared with educated mothers. Importantly, in 2014, the association between maternal education and infant mortality diminished, which could imply that the infants from uneducated mothers achieved a similar likelihood of survival that the infants from educated mothers enjoyed. This finding signifies that to reduce the burden of infant death, it might not be prudent to design different intervention programmes based on the educational level of the mothers. In 2011, maternal employment status was negatively contributing to infant survival. Past studies also showed that maternal employment can have an adverse effect on the care of a newborn, including infrequent breastfeeding and on personal care due to higher workload in performing the other traditionally ascribed roles within the family. ${ }^{41-43}$ However, in 2014, no adverse effect of maternal employment status was found on infant survival, which could imply that the newborn babies from both employed and unemployed mothers are enjoying somewhat equal levels of facilities until their first birth.

\section{Socioeconomic equity in infant survival}

In the context of Bangladesh, father is predominantly the main earner of the household. ${ }^{44}$ Thus, the father's occupation is a prerequisite for the living standards of families and allowing them to take essential care of the children. Similar to earlier studies ${ }^{12}{ }^{28}$ conducted in Bangladesh, we have observed a higher risk of infant mortality among unemployed fathers. Poor socioeconomic condition of the family leads to high infant deaths due to less utilisation of healthcare services during pregnancy and after birth. ${ }^{45}$ Study results revealed that from 2011 to 2014, urban areas achieved socioeconomic equity in infant survival, while the extent of inequity increased in rural areas. In terms of healthcare facilities, there exists a substantial gap between urban and rural areas of Bangladesh. ${ }^{21}$ People of urban areas enjoy far better healthcare facilities than rural people. ${ }^{21}$ Hence, in urban areas, women and children from comparatively poor households also get somewhat better access to maternal and child healthcare facilities (MCHF), which contributes enormously to improve the practice of using MCHF. Again, this higher practice of using MCHF also makes a positive environment in urban areas towards the usage of MCHF, which further contributes to improving the usage of MCHF. This cyclic pathway of improving the usage of MCHF could be a possible reason behind achieving an improvement in socioeconomic equity (regarding infant survival), in urban settings.

\section{Relationship between child factors and infant mortality}

Our findings showed that in the year 2011, the risk of infant death was significantly higher for male babies compared with females. The fact that girls have some biological advantage against many causes of early death than boys, ${ }^{47-50}$ which is due to a lesser vulnerability to perinatal conditions, congenital anomalies and infectious diseases. Despite these facts, in 2014, no association was found between the sex of the index child and mortality risk. First-order births in Bangladesh face inexperienced adolescent mothers due to early marriage. ${ }^{51}{ }^{52}$ According to the United Nations Population Fund's annual report $2019,{ }^{53}$ Bangladesh had the highest adolescent pregnancy rate outside Sub-Saharan Africa. The immature reproductive system of these adolescent mothers could contribute to a high infant mortality risk for their babies. Results of the present study also support this fact by revealing that after controlling the effect of maternal age on infant mortality no significant association was noticed between birth order and infant death.

\section{Role of parity on the association between place of residence and infant mortality}

Both in rural and urban settings, the majority of firstorder births face inexperienced adolescent mothers, ${ }^{20} 23$ which results in a similar level of death risk at first-order birth in both settings. For the first time our study revealed that in 2011, at higher birth orders, infants from urban areas experienced a greater likelihood of death compared with rural infants. This phenomenon could be well explained by the association between maternal age at childbirth and infant death. On average, urban mothers give birth to their first child later than rural mothers and also have longer birth intervals for subsequent births. ${ }^{23} 54$ Therefore, compared with the mothers from rural areas, urban mothers get comparatively older at higher birth orders, which may lead to a greater likelihood of infant death. In rural areas, the median age at first birth did not increase from 2011 to 2014, but the median birth interval increased from 45.9 months in 2011 to 50.5 months in $2014 .^{2023}$ This could imply that maternal age at third and higher parity also increased in rural areas. This could be a possible reason behind observing no significant 
differentials in infant mortality across the place of residence at third and higher parity in 2014.

\section{Limitations}

Several limitations to be considered while interpreting the study results. As we used cross-sectional data, the establishment of any causal relationship from this study is not possible. Several important contextual and biological factors such as quality and care of health facilities, cultural practice, customs, parental competence and maternal depletion could not be incorporated due to the unavailability of data in the DHS.

\section{CONCLUSION}

This study has effective policy implications especially in designing the intervention programmes to attain a sustainable improvement in infant survival. Reducing fatherhood at younger ages and reducing early pregnancy could reduce infant mortality at a faster pace. A special community-based awareness programme should be designed to enlighten the urban society regarding the infant death risk at higher order births. Scaling up the access and utilisation of MCHF in rural areas could substantially contribute to reducing the socioeconomic disparity in infant survival. In this regard, communitybased dedicated transportation facilities to reach MCHF could uptake the usage of MCHF among rural mothers from poor households.

Contributors MdMR: conception of the study and statistical analysis. MdMR and TA: design of the study. MdMR, TA and SM: drafted the manuscript. MdMR and NS: revised and edited the final manuscript. All the authors read and approved the manuscript.

Funding The authors have not declared a specific grant for this research from any funding agency in the public, commercial or not-for-profit sectors.

Competing interests None declared.

Patient and public involvement Patients and/or the public were not involved in the design, or conduct, or reporting, or dissemination plans of this research.

Patient consent for publication Not required.

Provenance and peer review Not commissioned; externally peer reviewed.

Data availability statement Data are available in a public, open access repository. Datasets used for this study was obtained from the DHS website (https:// dhsprogram.com/). Data are available publicly in this website. Datasets used for this study was obtained from the BDHS website (https://dhsprogram.com/). Data are available publicly in this website.

Open access This is an open access article distributed in accordance with the Creative Commons Attribution Non Commercial (CC BY-NC 4.0) license, which permits others to distribute, remix, adapt, build upon this work non-commercially, and license their derivative works on different terms, provided the original work is properly cited, appropriate credit is given, any changes made indicated, and the use is non-commercial. See: http://creativecommons.org/licenses/by-nc/4.0/.

\section{ORCID iDs}

Tasnim Ara http://orcid.org/0000-0003-4259-5113

Sultan Mahmud http://orcid.org/0000-0003-0757-7630

\section{REFERENCES}

1 Reproductive Health. Centers for disease control and prevention. Available: https://www.cdc.gov/reproductivehealth/ maternalinfanthealth/infantmortality.htm [Accessed 1 Sep 2020].
2 Kabir M, Amin R. Factors influencing child mortality in Bangladesh and their implications for the National health programme. Asia Pac Popul J 1993;8:1-9.

3 Shah M, Khalique N, Khan Z, et al. A community based study of infant mortality in rural Aligarh. Australas Med J 2011;4:22-5.

4 Mortality rate per infant. The world bank. Available: https://data. worldbank.org/indicator/SP.DYN.IMRT.IN [Accessed 2 Sep 2020].

5 Ahmed T, Mahfuz M, Ireen S, et al. Nutrition of children and women in Bangladesh: trends and directions for the future. $J$ Health Popul Nutr 2012;30:1.

6 World Health Organization \& Bangladesh. Ministry of Health and Family Welfare. Success factors for women's and children's health: Bangladesh. World Health Organization, 2015. https://apps.who.int/ iris/handle/10665/178623

7 Rahman KM, Sarkar P. Determinants of infant and child mortality in Bangladesh. Pakistan Journal of Social Sciences 2009;6:175-80.

8 Minnery M, Firth S, Hodge A, et al. Neonatal mortality and inequalities in Bangladesh: differential progress and sub-national developments. Matern Child Health J 2015;19:2038-47.

9 Majumder AK, May M, Pant PD. Infant and child mortality determinants in Bangladesh: are they changing? J Biosoc Sci 1997;29:385-99.

10 Hong R. Effect of multiple birth on infant mortality in Bangladesh. $J$ Paediatr Child Health 2006;42:630-5.

11 Chowdhury AH, Hanifi SMA, Mia MN, et al. Socioeconomic inequalities in under-five mortality in rural Bangladesh: evidence from seven national surveys spreading over 20 years. Int J Equity Health 2017;16:197.

12 Mondal MNI, Hossain MK, Ali MK. Factors influencing infant and child mortality: a case study of Rajshahi district, Bangladesh. J Hum Ecol 2009;26:31-9.

13 Agha S. The determinants of infant mortality in Pakistan. Soc Sci Med 2000;51:199-208.

14 Kembo J, van Ginneken JK. Determinants of infant and child mortality in Zimbabwe: results of multivariate hazard analysis. Demogr Res 2009;21:367-84.

15 Das Gupta M, clustering D. Death Clustering, Mothers' Education and the Determinants of Child Mortality in Rural Punjab, India. Popul Stud 1990;44:489-505.

16 Mustafa H. Socioeconomic determinants of infant mortality in Kenya: analysis of Kenya DHS 2003. Journal of Humanities \& Social Science 2008;2:1934-722.

17 Suwal JV. The main determinants of infant mortality in Nepal. Soc Sci Med 2001;53:1667-81.

18 Aksit B, Aksit B. Sociocultural determinants of infant and child mortality in turkey. Soc Sci Med 1989;28:571-6.

19 Chen X-K, Wen SW, Krewski D, et al. Paternal age and adverse birth outcomes: teenager or $40+$, who is at risk? Hum Reprod 2008:23:1290-6.

20 National Institute of Population Research and Training (NIPORT). Mitra and associates, ICF international. Bangladesh demographic and health survey 2014. Dhaka, Bangladesh and Rockville, Maryland, USA: NIPORT, Mitra and Associates, and ICF International, 2015.

21 Bangladesh Bureau of Statistics (BBS). Ministry of Planning, Government of the People's Republic of Bangladesh. Household Income and Expenditure Survey 2010 www.bbs.gov.bd

22 Kamal N, Curtis S, Hasan MS, et al. Trends in equity in use of maternal health services in urban and rural Bangladesh. Int $J$ Equity Health 2016;15:1.

23 National Institute of Population Research and Training (NIPORT). Mitra and associates, ICF international. Bangladesh demographic and health survey 2011. Dhaka, Bangladesh and Rockville, Maryland, USA: NIPORT, Mitra and Associates, and ICF International, 2013.

24 Nath SR. Exploring the marginalized: a study in some selected upazilas of Sylhet division in Bangladesh, research and evaluation division, brac, 2013. Available: http://research.brac.net/publi cations/ Exploring_the_Marginalized.pdf [Accessed 15 Aug 2020].

25 Alam N. Teenage motherhood and infant mortality in Bangladesh: maternal age-dependent effect of parity one. J Biosoc Sci 2000;32:229-36.

26 Khan JR, Awan N. A comprehensive analysis on child mortality and its determinants in Bangladesh using frailty models. Arch Public Health 2017;75:58.

27 Karmaker SC, Lahiry S, Roy DC, et al. Determinants of infant and child mortality in Bangladesh: time trends and comparisons across South Asia. Bangladesh Journal of Medical Science 2014;13:431-7.

28 Rahman MS, Rahman MS, Rahman MA. Determinants of death among under- 5 children in Bangladesh. Journal of Research and Opinion 2019;6:2294-302. 
29 Mantel N. Evaluation of survival data and two new RANK order statistics arising in its consideration. Cancer Chemother Rep 1966;50:163-70.

30 Cox DR. Regression models and life-tables. Journal of the Royal Statistical Society: Series B 1972;34:187-202.

31 Dwomoh D, Amuasi S, Agyabeng K, et al. Understanding the determinants of infant and under-five mortality rates: a multivariate decomposition analysis of demographic and health surveys in Ghana, 2003, 2008 and 2014. BMJ Glob Health 2019;4:e001658.

32 Trussell J, Hammerslough C. A hazards-model analysis of the covariates of infant and child mortality in Sri Lanka. Demography 1983;20:1-26.

33 Miller JE. Birth Outcomes by Mother's Age At First Birth in the Philippines. Int Fam Plan Perspect 1993;19:98-102.

34 Solís P, Pullum SG, Frisbie WP. Demographic models of birth outcomes and infant mortality: an alternative measurement approach. Demography 2000;37:489-98.

35 Pebley AR, Millman S. Birthspacing and child survival. Int Fam Plan Perspect 1986;12:71-9.

36 Lerman RI. A national profile of young unwed fathers. Young unwed fathers: Changing roles and emerging policies, 1993: 27-51.

37 Lerman RI. Employment patterns of unwed fathers and public policy. Young unwed fathers: Changing roles and emerging policies, 1993: 316-34

38 Caldwell JC. Education as a factor in mortality decline an examination of Nigerian data. Popul Stud 1979;33:395-413.

39 Caldwell JC. How is greater maternal education translated into lower child mortality? Health transition review 1994;4:224-9 http://www. jstor.org/stable/40652138

40 Kuhn R, Caldwell JC. Routes to low mortality in poor countries revisited. Popul Dev Rev 2010;36:655-92.

41 Reid A. Neonatal mortality and stillbirths in early twentieth century Derbyshire, England. Popul Stud 2001;55:213-32.
42 Titaley CR, Dibley MJ, Agho K, et al. Determinants of neonatal mortality in Indonesia. BMC Public Health 2008;8:232

43 Ahmad-Nia S. Women's work and health in Iran: a comparison of working and non-working mothers. Soc Sci Med 2002;54:753-65.

44 Rahman A. Significant risk factors for childhood malnutrition: evidence from an Asian developing country. Sci J Public Health 2016;4:16-27.

45 Vijay J, Patel KK. Risk factors of infant mortality in Bangladesh. Clin Epidemiol Glob Health 2020;8:211-4.

46 Singh A, Pathak PK, Chauhan RK, et al. Infant and child mortality in India in the last two decades: a geospatial analysis. PLoS One 2011;6:e26856.

47 Alonso V, Fuster V, Luna F. Causes of neonatal mortality in Spain (1975-98): influence of sex, rural-urban residence and age at death. $J$ Biosoc Sci 2006;38:537-51.

48 DaVanzo J, Butz WP, Habicht J-P. How biological and behavioural influences on mortality in Malaysia vary during the first year of life. Popul Stud 1983;37:381-402.

49 Bhuiya A, Streatfield K. Mothers' Education and Survival of Female Children in a Rural Area of Bangladesh. Popul Stud 1991;45:253-64.

50 Sawyer CC. Child mortality estimation: estimating sex differences in childhood mortality since the 1970s. PLoS Med 2012;9:e1001287.

51 Rah JH, Christian P, Shamim AA, et al. Pregnancy and lactation hinder growth and nutritional status of adolescent girls in rural Bangladesh. J Nutr 2008;138:1505-11.

52 Sayem AM, Nury ATMS. Factors associated with teenage marital pregnancy among Bangladeshi women. Reprod Health 2011;8:1-6.

53 Bangladesh U. UNFPA Bangladesh annual report 2019, 2020. Available: www.bangladesh.unfpa.org [Accessed 10 May 2020]

54 Khan JR, Bari W, Latif AM. Trend of determinants of birth interval dynamics in Bangladesh. BMC Public Health 2016;16:1. 